\title{
An Efficient Biosorption of Direct Dyes from Industrial Wastewaters Using Pretreated Sugarcane Bagasse
}

\author{
Abd El-Aziz Ahmed Said ${ }^{1, *}$, Aref Ahmed M.Aly ${ }^{1}$, Mohamed Mahmoud Abd El-Wahab ${ }^{1}$, Soliman Abd \\ El-Fadeel Soliman ${ }^{1}$, Aly Ahmed Abd El-Hafez ${ }^{1}$, Victor Helmey ${ }^{2}$, Mohamed Nady Goda ${ }^{1}$ \\ ${ }^{1}$ Department of Chemistry, Faculty of Science, Assiut University, Assiut, Egypt \\ ${ }^{2}$ Department of Mechanical Engineering, Faculty of Engineering, Assiut University, Assiut, Egypt \\ *Corresponding Author: aasaid55@yahoo.com
}

Copyright (C) 2013 Horizon Research Publishing All rights reserved.

\begin{abstract}
This research work involved the use of the low cost, available and renewable biosorbent propionic acid pretreated bagasse for the removal of the textile direct yellow 12 and direct red 81 dyes from aqueous solutions. Batch experiments were carried out for sorption kinetics and isotherms of the two dyes. The studied operating variables include initial $\mathrm{pH}$, contact time, initial dye concentration, adsorbent dose and particle size. Maximum color removal was in acidic medium $(\mathrm{pH}$ 2.5-3.5) where a greater percentage removal was observed in this $\mathrm{pH}$ range. Equilibrium isotherms were applied using Langmuir and Freundlich models of adsorption and it was found that the Langmuir isotherm was the best model for adsorption of direct yellow 12 whereas the Freundlich model was suitable for adsorption of the direct red 81. The kinetics of adsorption of both dyes was consistent with a pseudo-first order kinetic for the direct yellow 12 and a pseudo-second order for the direct red 81. Desorption of both dyes is greatly dependent on the $\mathrm{pH}$ value of the solution with which the bagasse loaded dye in contact. The percent dye removal increases with the $\mathrm{pH}$ increase.
\end{abstract}

Keywords Sugarcane Bagasse, Direct Red 81, Direct Yellow 12, Ph, Desorption, Kinetics

\section{Introduction}

Color is the first contaminant to be recognized in the industrial wastewater and the presence of even small amounts of dyes in water is highly visible and undesirable [1, 2]. Owing to the low biodegradation of dyes, the conventional biological treatment process is not very effective in dye removal from wastewater. A number of physical or chemical processes were applied for dye treatment. These include coagulation and chemical oxidation, membrane separation process, electrochemical and reverse osmosis. However, all these methods include limitations and are useful for complete removal of dye from wastewater, but unfortunately these processes are very expensive [3].

Currently, there is a growing interest in using low cost sorbents for dye removal. These are agricultural waste products like sawdust [4], wheat straw [5], coir pith [6], sugar cane bagasse $[7,8]$ and others. Some of these materials were chemically modified for improving their adsorption capacity $[9,10]$.

Direct dyes are characterized with their high conjugated molecular structure and they contain one or more anionic sulphate groups which aid in solubility of the dye molecule in water. Many papers were concerned with the investigation of the removal of direct dyes adoapting various biosorbents [11-13].

The present study deals with the use of propionic acid treated bagasse as a low cost and efficient biosorbent for the removal of direct yellow 12 (I) and direct red 81 (II) (Fig. (1)) from aqueous solutions and optimizing the various parameters influencing the sorption capacity of this biosorbent.
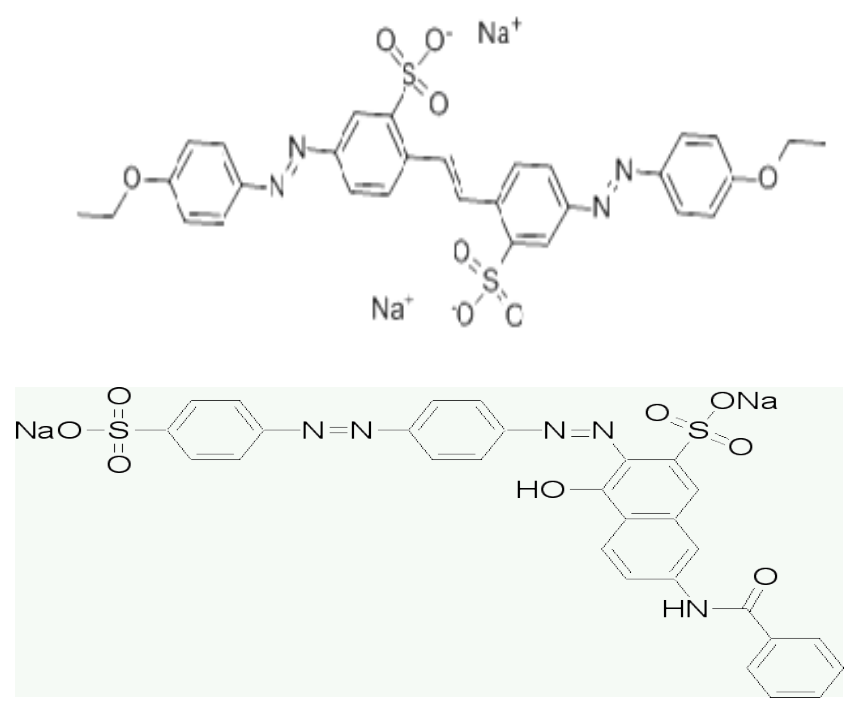

Figure 1. Chemical structure of direct yellow 12 (I) and direct red 81 (II) 


\section{Materials and Methods}

\subsection{Preparation of Propionic Acid Pretreated Bagasse}

Sugarcane bagasse supplied from Egyptian sugar company and integrated industries was repeatedly washed with distilled water in order to remove dust and soluble impurities. It was dried overnight at $60^{\circ} \mathrm{C}$ before crushing, shredding and seaving with different particle size range of $(0.25-1 \mathrm{~mm})$. The propionic acid modified bagasse was prepared by mixing 5 wt. $\%$ acid with raw bagasse and then dried in an oven at $60^{\circ} \mathrm{C}$ overnight. The chemicals used throughout this work were of analytical grades. All measurements were performed using a $\mathrm{pH}$-meter model number JENWAY-3450. The initial $\mathrm{pH}$ values were adjusted with $0.1 \mathrm{M}$ of $\mathrm{HCl}$ or $\mathrm{NaOH}$. Concentration of dye solutions was determined using a thermofisher scientific aquamate evolution $166 \mathrm{UV}-$ Visible spectrophotometer.

\subsection{Adsorption and Kinetic Studies}

The experiments on the two dyes were conducted in 100 $\mathrm{mL}$ Erlenmeyer flasks containing $50 \mathrm{~mL}$ of the dye solution of known concentration and one gram of the adsorbent at the appropriate $\mathrm{pH}$ and agitated by a mechanical shaker at room temperature. After a definite time interval, the solution was filtered and the filtrate thus obtained was analyzed spectrophotometrically by measuring the absorbance at $\lambda_{\max }$ of each dye. All the experiments were duplicated and the mean values were reported. The maximum deviation observed was less than $\pm 5 \%$. In the adsorption kinetic experiments samples were taken to measure the dye removal at predetermined time intervals. The amount of dye biosorbed per unit mass was calculated using the following equation:

$$
\mathrm{q}=\left(\mathrm{C}_{\mathrm{o}}-\mathrm{C}_{\mathrm{e}}\right) * \mathrm{~V} / \mathrm{W}
$$

where $\mathrm{q}$ is the amount of adsorbed dye $(\mathrm{mg} / \mathrm{g}), \mathrm{C}_{\mathrm{o}}$ and $\mathrm{C}_{\mathrm{e}}$ are the initial and equilibrium concentration, respectively. $\mathrm{V}$ is the volume of the solution $(\mathrm{mL})$ and $\mathrm{W}$ is the amount of the biosorbent (g).

\section{Results and Discussion}

\subsection{Effect of Initial pH}

The effect of $\mathrm{pH}$ is an important factor to control the adsorption of dye onto the adsorbent. Dyes exist in an ionic form in aqueous solutions. So, the degree of their adsorption on the adsorbent surface is influenced by the charge on the adsorbent, which in turn is affected by solution $\mathrm{pH}$. From Fig. (2), it can be concluded that the maximum biosorption of direct yellow 12 and direct red 81 occurs at $\mathrm{pH}=3.2$ and $\mathrm{pH}=2.5$, respectively. It is suggested that at lower $\mathrm{pH}$, the biosorbent surface is positively charged and thus an electrostatic attraction develops between the positively charged bagasse and the negatively charged anionic direct dye [14]. It is worth noting here that, the direct red 81 dye is strongly affected by the change of $\mathrm{pH}$ than that of direct yellow 12. Moreover, the higher removal of direct red 81 at a lower $\mathrm{pH}$ value may be attributed to the presence of active sites on the treated bagasse which are accessible for direct red 81 dye adsorption than for direct yellow 12 .

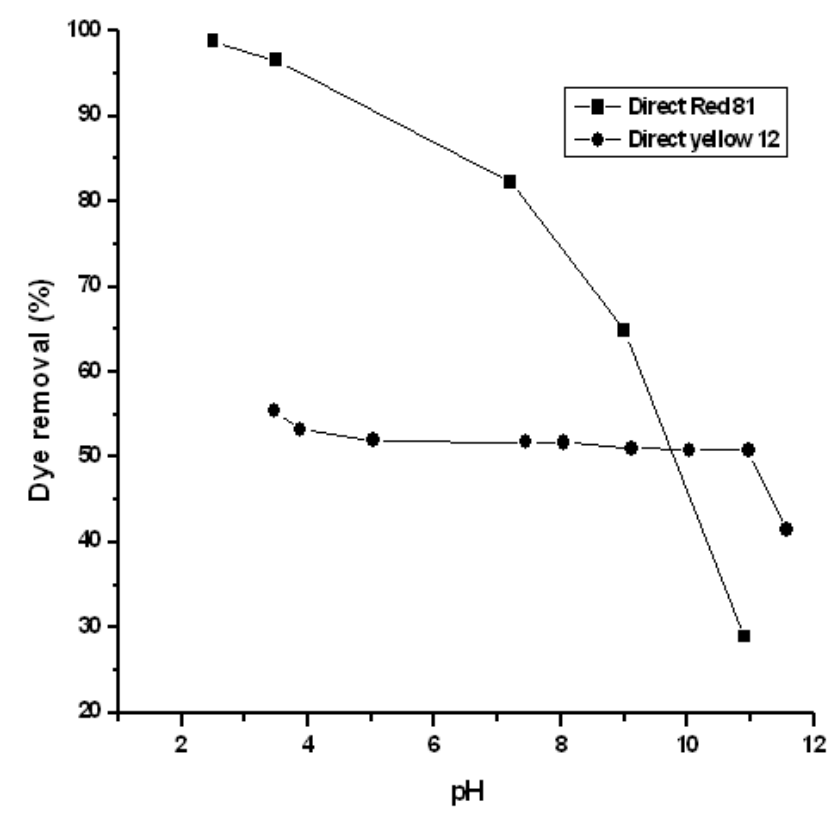

Figure 2. Variation of $\%$ dye removal with $\mathrm{pH}$ for direct yellow 12 and direct red 81 .

\subsection{Effect of Contact Time}

The contact time between biosorbent and the dye signifies the efficiency of the biosorbent. The effect of contact time is presented in Fig. (3). The uptake of both dyes was rapid in the first 20 minutes and after 75 minutes the amounts of both dyes were almost constant. The two curves of contact time were single, smooth and continuous until reaching saturation, suggesting possible monolayer coverage of both dyes on the surface of modified bagasse [15].The first rapid uptake can be rationalized as a rapid attachment of both dyes to the biosorbent surface or due to the large number of vacant sites available at the initial stage.

\subsection{Effect of Initial Dye Concentration}

The effect of the initial direct yellow 12 and direct red 81 concentrations on the adsorption capacity $(\mathrm{mg} / \mathrm{g})$ was studied and the results are depicted in Fig. (4). From these curves one can notice that as the initial concentration of both dyes increases, the adsorption capacity increases. This behavior suggests that available sites on the biosorbent are 
the limiting factor for the dye removal [16].

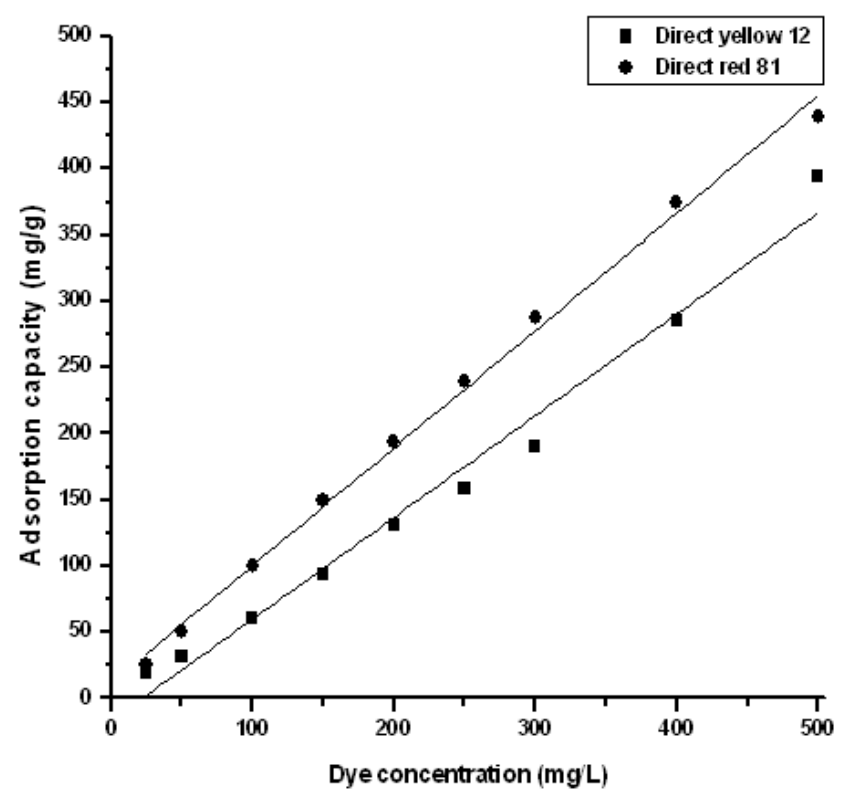

Figure 3. Variation of $\%$ dye removal with contact time for direct yellow 12 and direct red 81 .

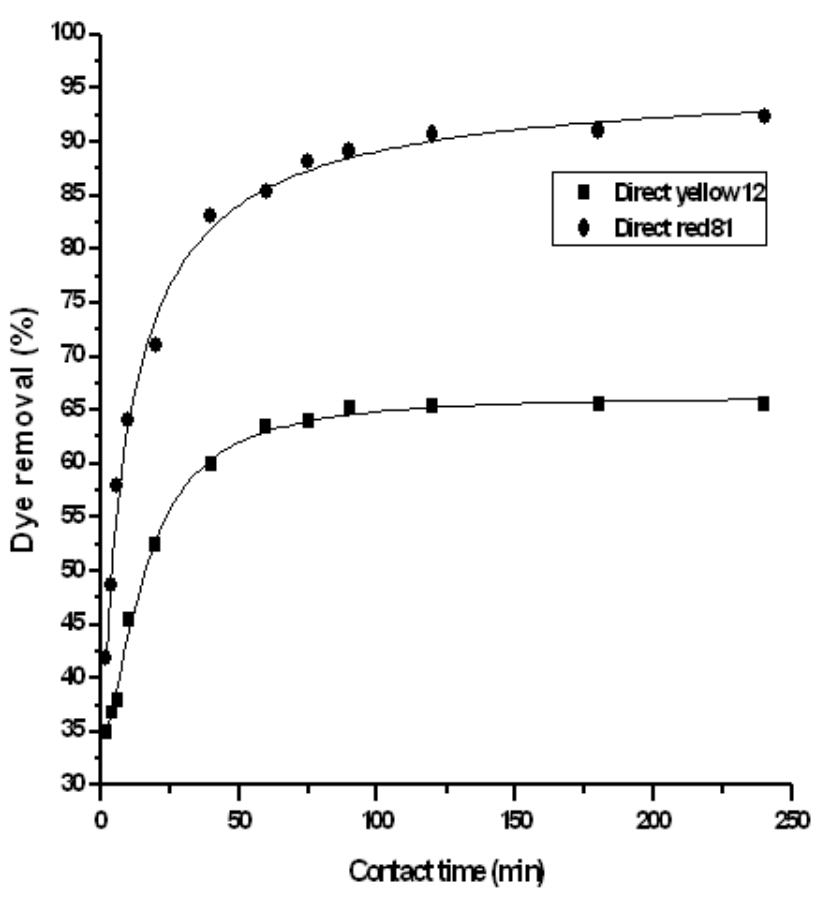

Figure 4. Variation of sorption capacity as a function of dye concentration for direct yellow 12 and direct red 81 .

\subsection{Effect of Adsorbent Dosage}

The effect of pretreated bagasse dosage on the removal of direct yellow 12 and direct red 81 was studied and presented in Fig. (5). The figure reveals an increase of the percentage removal of the dye as the amount of bagasse was varied from $0.2-2 \mathrm{~g}$. This may be attributed to the increase in the availability of surface active sites with the dose increase.

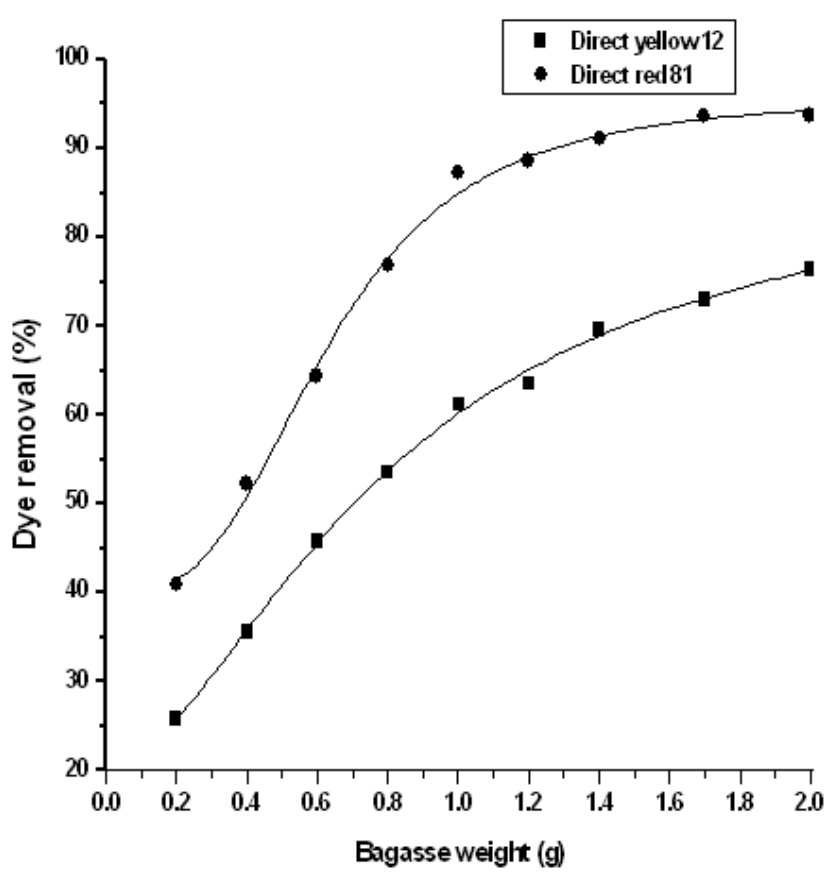

Figure 5. Variation of \%dye removal with bagasse weight for direct yellow 12 and direct red 81 .

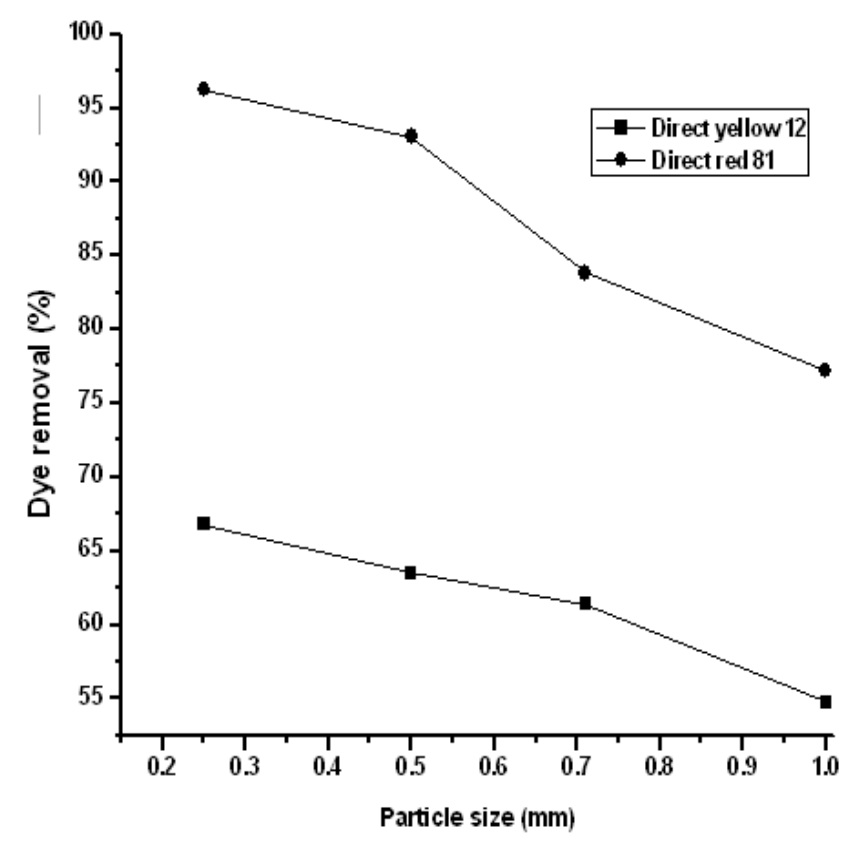

Figure 6. Variation of $\%$ dye removal with particle size of treated bagasse for direct yellow 12 and direct red 81 .

\subsection{Effect of Particle Size}

Adsorption of direct yellow 12 and direct red 81 on four sized particles, namely $0.25,0.5,0.75$ and $1 \mathrm{~mm}$ of treated bagasse was studied. The results are shown in Fig. (6). The figure indicates that as the particle size increases the percentage of dye removal decreases. Decrease in particle size leads to an increase of available active sites on the 
surface of the biosorbent and consequently an increase in the adsorption process at the outer surface of bagasse. Furthermore, the diffusional resistance to mass transfer increases as the particle size increases. For this reason and for other reasons such as diffusional path length, contact time and blocked parts of the particles not available for adsorption, the adsorption capacity of the large particles becomes low [17].

\subsection{Adsorption Isotherm}

The adsorption isotherms are based on the assumption that every adsorption site is equivalent. The parameters deduced from the different isotherms provide valuable information regarding the adsorption mechanism as well as the surface properties and characteristics of the adsorbent. Langmuir and Freundlich models are two acceptable models for studying such single state systems.

\section{Freundlich isotherm}

Freundlich isotherm is expressed as follows:

$$
\text { qe }=\mathrm{KF} \mathrm{Ce} 1 / \mathrm{n}
$$

where qe $(\mathrm{mg} / \mathrm{g})$ is the amount of dye adsorbed at equilibrium, $\mathrm{Ce}(\mathrm{mg} / \mathrm{L})$ is the equilibrium liquid- phase concentration of the dye and $\mathrm{KF}$ is a constant related to the bonding energy and adsorption capacity. $1 / \mathrm{n}$ indicates the adsorption intensity of dye onto the adsorbent and the type of isotherm can be irreversible $(1 / \mathrm{n}=0)$, favorable $(0<1 / \mathrm{n}$ $<1)$ and unfavorable $(1 / \mathrm{n}>1)$. Equation (2) can be arranged to a linear form:

$$
\log \mathrm{qe}=\log \mathrm{KF}+(1 / \mathrm{n}) \log \mathrm{Ce}
$$

\section{Langmuir isotherm}

The Langmiur equation is expressed as follows:

$$
\mathrm{qe}=\mathrm{a} \mathrm{Qm} \mathrm{Ce} /(1+\mathrm{a} \mathrm{Ce})
$$

where qe and $\mathrm{Ce}$ are defined as in the Freundlich equation, $\mathrm{Qm}$ is the maximum adsorption capacity and " $\mathrm{a}$ " is the Langmiur constant. Its linear form is expressed as:

$$
\mathrm{Ce} / \mathrm{qe}=(1 / \mathrm{a} \mathrm{Qm})+(\mathrm{Ce} / \mathrm{Qm})
$$

The Qm and a values can be obtained from the slope $(1 / \mathrm{Qm})$ and the intercept $(1 / \mathrm{a} \mathrm{Qm})$ of the linear plot $\mathrm{Ce} / \mathrm{qe}$ versus $\mathrm{Ce}$.

Freundlich and Langmuir linear isotherms are presented for direct yellow 12 and direct red 81, respectively, in Fig. 7 (a\&b). The coefficient isotherm parameters for both dyes are cited in Table 1.

The correlation coefficients appearing in Table 1 show the efficiency of the propionic acid modified bagasse towards removal of both direct dyes. The data in Table 1 reveal that the Freundlich isotherm is suitable as a model for the direct yellow 12 adsorption whereas the Langmuir isotherm proved to be the best fit model for direct red 81 .
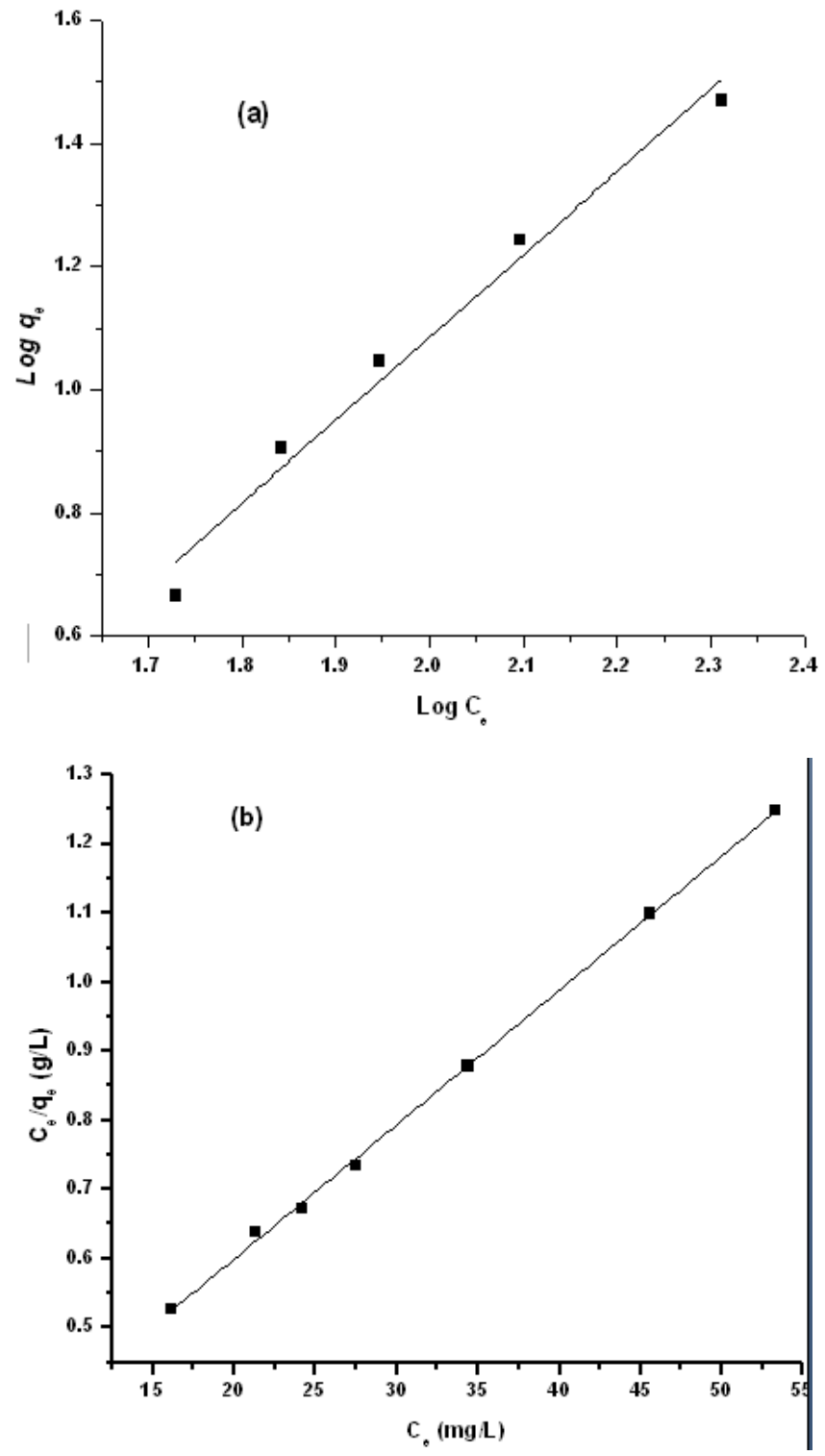

Figure 7. Linear plots of the Freundlich isotherm for direct yellow 12 (a) and the Langmuir isotherm for direct red 81 (b).

Table 1. Freundlich and Langmuir parameters for direct yellow 12 and direct red 81 removal.

\begin{tabular}{|c|c|c|c|c|c|c|}
\hline \multirow{2}{*}{ Dye } & \multicolumn{3}{|c|}{ Freundlich } & \multicolumn{3}{c|}{ Langmuir } \\
\cline { 2 - 7 } & $\mathrm{R}^{2}$ & $\mathrm{~K}_{\mathrm{F}}$ & $\mathrm{n}$ & $\mathrm{R}^{2}$ & $\mathrm{a}$ & $\mathrm{Q}_{\mathrm{m}}$ \\
\hline Direct yellow 12 & 0.9754 & 0.025 & 0.7443 & - & - & - \\
\hline Direct red 81 & - & - & - & 0.9989 & 0.0923 & 51.44 \\
\hline
\end{tabular}



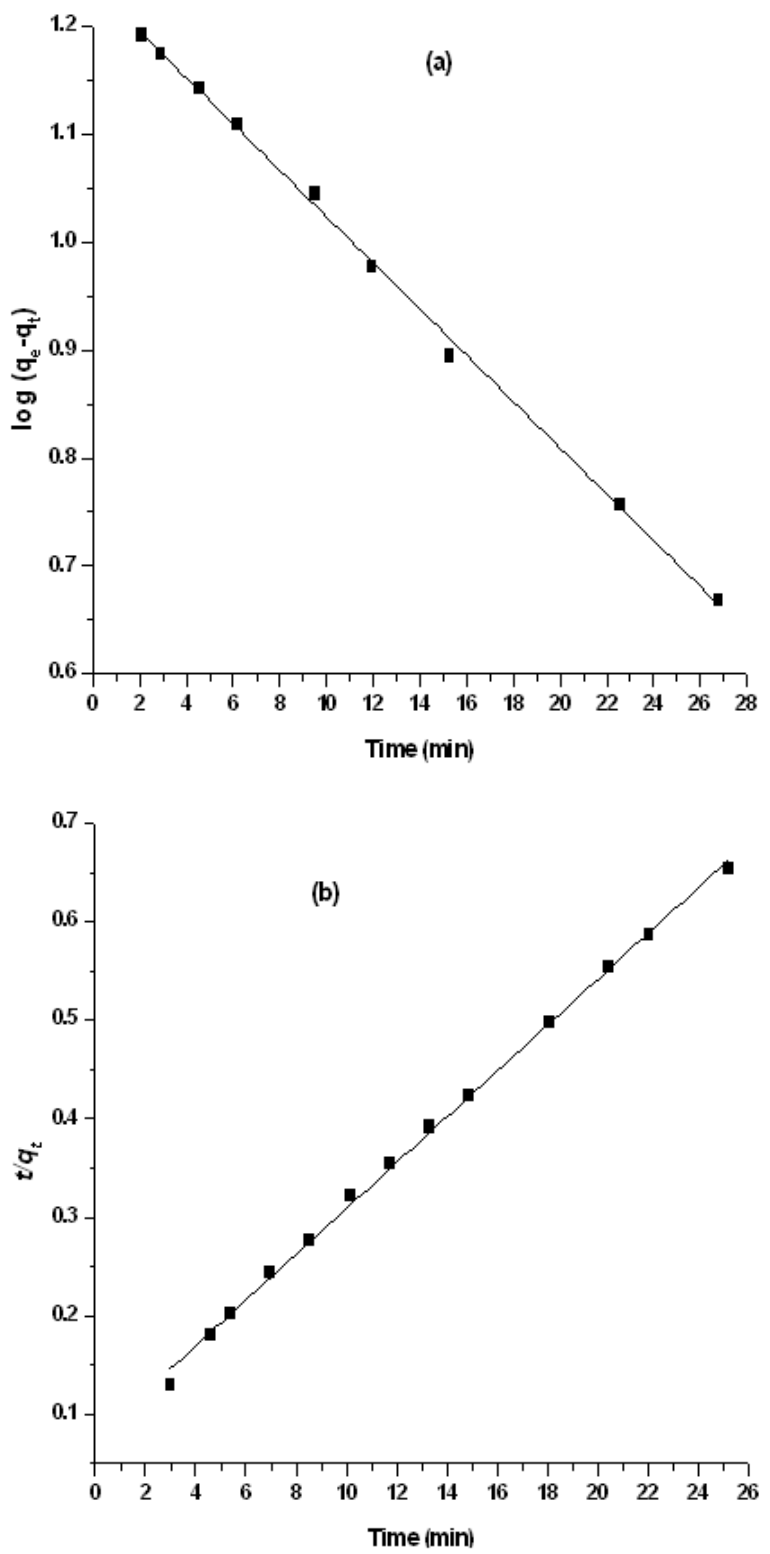

Figure 8. pseudo-first order plot for direct yellow 12 (a) and pseudo-second order plot for direct red 81 (b).

\subsection{Adsorption Kinetic Study}

The experimental data were tested with pseudo-first order and pseudo-second order kinetic models in order to understand the kinetics of the two dyes removal by the pretreated propionic bagasse. Pseudo-first order (equation 6) and pseudo-second order (equation 7) rate equations are expressed as follows:

$$
\log (\mathrm{qe}-\mathrm{qt})=\log \mathrm{qe}-\mathrm{k} 1 \mathrm{t} / 2.303
$$

and

$$
\mathrm{t} / \mathrm{qt}=1 / \mathrm{h}+\mathrm{t} / \mathrm{qe}
$$

where qe is the amount of dye sorbed at equilibrium $(\mathrm{mg} /$ $\mathrm{g})$, qt is the amount of dye sorbed at time $\mathrm{t}(\mathrm{mg} / \mathrm{g}), \mathrm{k} 1$ is the rate constant of the pseudo-first order kinetic $(\min -1), \mathrm{h}$ (k2qe2) is the initial adsorption rate ( $\mathrm{mg} / \mathrm{g}$ min) and $\mathrm{k} 2$ is the rate constant of pseudo-second order kinetics $(\mathrm{mg} / \mathrm{g}$ $\min )$.
The straight lines obtained for the two dyes are presented in Figure $8(\mathrm{a} \& \mathrm{~b})$. These figures indicate the applicability of the above two equations. It is apparent from the two figures that the kinetics of direct yellow 12 obey the pseudo-first order kinetic model whereas direct red 81 follows that of pseudo-second order one. The values of $\mathrm{k} 1$ and $\mathrm{k} 2$ were calculated from the slope and intercept of the respective linear plot and are recorded in Table 2.

Table 2. Pseudo first order and second order parameters for direct yellow 12 and direct red 81 removal.

\begin{tabular}{|c|c|c|c|}
\hline Dye & $\mathrm{R}^{2}$ & $\mathrm{~K}_{1}\left(\mathrm{~min}^{-1}\right)$ & $\mathrm{K}_{2}\left(\mathrm{mgg}^{-1} \mathrm{~min}^{-1}\right)$ \\
\hline $\begin{array}{c}\text { Direct yellow } \\
12\end{array}$ & 0.9982 & 0.0494 & - \\
\hline Direct red 81 & 0.9981 & - & 0.0071 \\
\hline
\end{tabular}

\subsection{Intra-particle Diffusion Study}

An empirical function relationship was formulated by Weber-Morris [18] which is common to most adsorption processes with the uptake varies almost proportionally with $\mathrm{t} 1 / 2$ as the following equation:

$$
\mathrm{qt}=\mathrm{Kid} \mathrm{t} 1 / 2+\mathrm{C}
$$

where Kid is the intra-particle diffusion rate constant, qt (mg g-1) is the amount of dye adsorbed at time $\mathrm{t}(\mathrm{min})$. A plot of qt versus $t 1 / 2$ should be a straight line with a slope Kid and intercept $\mathrm{C}$.Values of intercept give an idea about the thickness of the boundary layer, i.e., the larger the intercept the greater the boundary layer effect [19].

Fig. 9 (a\&b) shows a plot of the amount of adsorbed direct yellow 12 and direct red 81 (qt) vs. t1/2. The two graphs revealed that ech dye displays two separate regions with two intersecting straight lines. When the line passes through the origin $(C=0)$, this means that the intra-particle diffusion is the only rate controlling step. That the line does not pass through the origin indicate that other processes may control the sorption rate [20]. The first straight portion of the graph is attributed to the macropore diffusion while the second linear portion is correlated with the micropore diffusion. It is also clear from Fig. (9) that the first stage is faster than the second one, which may be ascribed to the very slow diffusion of the dye from the surface film into the micropores which represent the least accessible sites for adsorption.

\subsection{Desorption Studies}

Desorption studies are important in exploring the mechanism of adsorption and the possibility of dye and sorbent recovery. Therefore, desorption experiments were performed on samples of direct yellow 12 and direct red 81 loaded bagasse by gentle washing with water to remove the unadsorbed dye, then the samples were agitated with distilled water adjusted to different $\mathrm{pH}$ values. The desorbed dye was then separated and estimated. The percent desorption increases with the increase in medium $\mathrm{pH}$ which is just the opposite to the pH effect (Fig. 10 (a\&b)). 

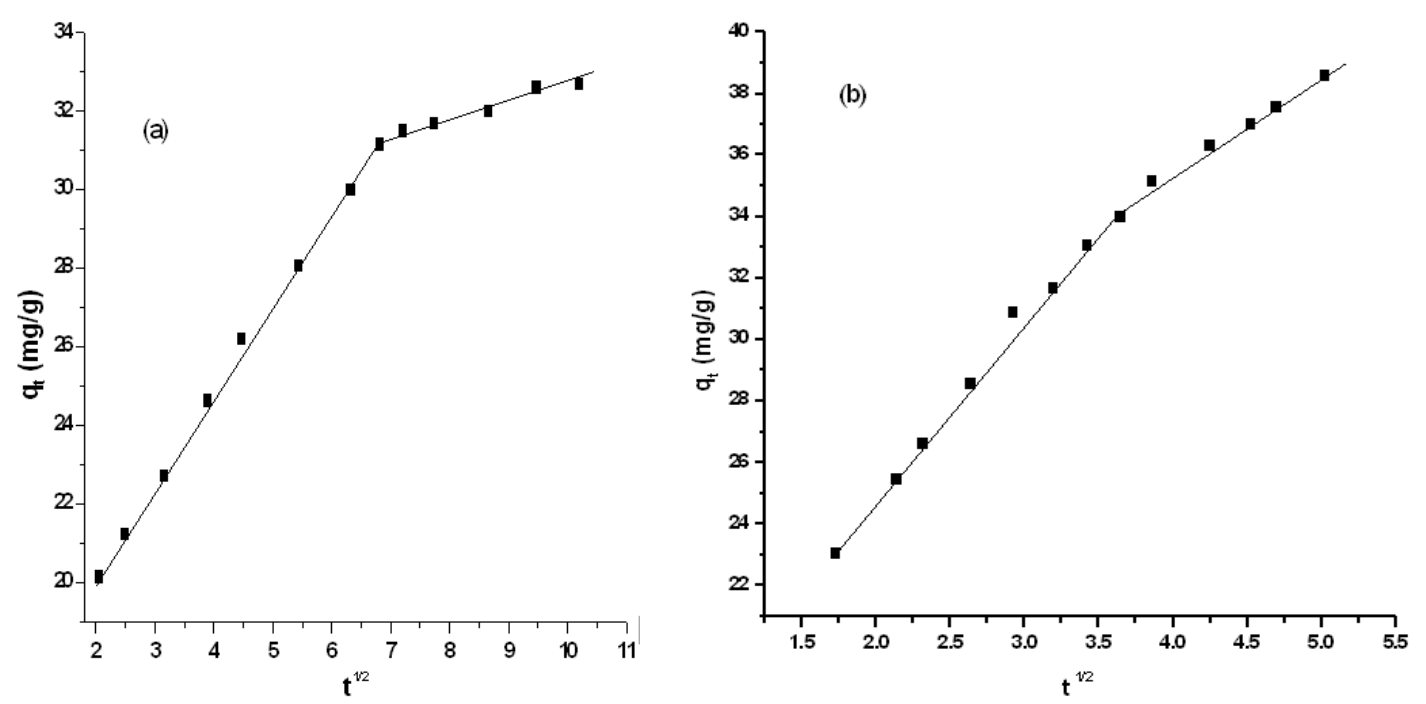

Figure 9. Intra-particle diffusion model representation (a) direct yellow 12 and (b) direct red 81.

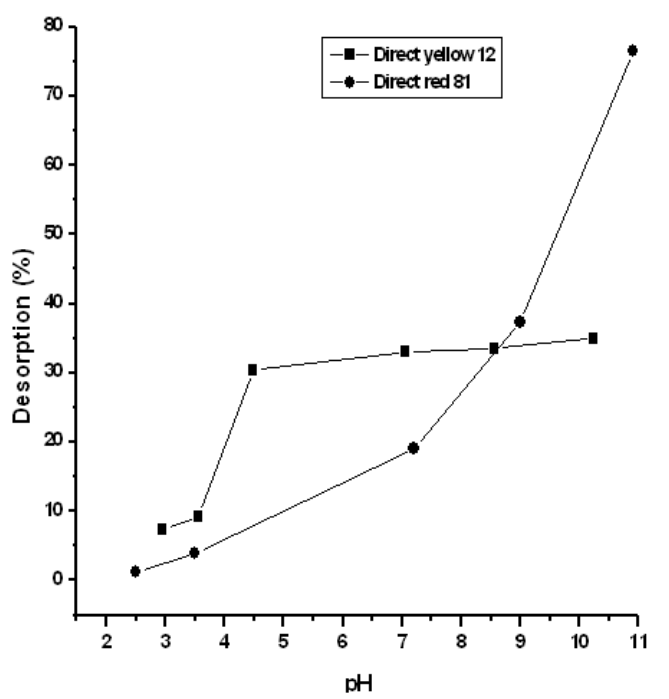

Figure 10. Desorption study for direct yellow 12 and direct red 81

It is important to mention here from the results depicted in Fig. (10) that the recovery of treated bagasse contaminated with direct red 81 is possible in basic medium. On the other hand the recovery of bagasse contaminated with direct yellow 12 seems to be difficult. This is may account to the strong bond formed between the dye and the biosorbent.

However, comparison of the propionic acid pretreated bagasse with other biosorbents for direct dyes removal revealed that it can be considered as a promising biomaterial for the removal of this class of dyes and Table 2 contains a comparison between the Freundlich and Langmuir parameters of this work and those of other biosorbents.

Comparison between our sorbent and other sorbents for direct dyes removal is listed in Table (3).

Table 3. Comparison of adsorption isotherm characteristic between propionic acid pretreated bagasse and other sorbents for direct dye removal

\begin{tabular}{|c|c|c|c|c|c|}
\hline \multirow{2}{*}{ Sorbent } & \multirow{2}{*}{ Dye } & Langmuir $\left(\mathrm{Q}_{\mathrm{m}}\right)$ & \multicolumn{2}{|c|}{ Freundlich } & \multirow{2}{*}{ Reference } \\
\cline { 4 - 5 } & Direct red & 5.92 & - & - & 21 \\
\hline Banana pith & Congo red & 14.72 & - & - & 22 \\
\hline $\begin{array}{c}\text { Dead fungus } \\
\text { Aspergillus }\end{array}$ & Direct blue 86 & 33.78 & - & - & 14 \\
\hline $\begin{array}{c}\text { AC orange } \\
\text { Peel }\end{array}$ & (Congo red) & - & 1.46 & 1.20 & 23 \\
\hline $\begin{array}{c}\text { Waste banana } \\
\text { pith }\end{array}$ & & - & 1.82 & 1.21 & 24 \\
\hline Wollestonite & Direct yellow12 & - & 0.74 & 0.025 & - \\
\hline This work & Direct red 81 & 51.44 & - & - & 2 \\
\hline
\end{tabular}




\section{Conclusion}

Based on the above findings and arguments, it is to be concluded that propionic acid pretreated bagasse could be employed as an effective and inexpensive sorbent for the removal of direct dyes. But in fact this sorbent possesses a more significant efficiency on the removal of direct red 81 than that of direct yellow 12 .

\section{Acknowledgements}

The authors would like to thank the financial support from the Science Technology Development Fund, STDF, Ministry of Higher Education, Egypt.

\section{REFERENCES}

[1] I. B. Banat, P. Nigam, D. Singh, R. Marchant, Microbial decolorization of textile-dye-containing effluents: A review. Bioresource Technology 58, 217-227, 1996.

[2] T. Robinson, G. MoMullan, R. Marchant, P. Nigam, Remediation of dyes in textile effluent: A critical review on current treatment technologies with a proposed alternative. Bioresource Technology. 77, 247-255, 2001.

[3] V. K. Gupta and Suhas, Application of low-cost adsorbents for dye removal-A review, Journal of Environmental Management 90, 2313-2342, 2009.

[4] A. Shukla, Y. Hui Zhang, P. Dubey, J. L. Margrave, S. S. Shukla, The role of sawdust in the removal of unwanted materials from water. Journal of Hazardous Materials B95, 137-152, 2002.

[5] T. Robinson, B. Chandran, P. Nigam, Studies on desorption of individual textile dyes and a synthetic dye effluent from dye-adsorbed agricultural residues using solvents. Bioresource Technology, 84, 299-301, 2002.

[6] R. N. Prasad, S. Viswanathan, J. R. Devi, J. Rajkumar, N. Parthasathy, Kinetics and equilibrium studies on biosorption of CBB By coir pith. Am.-Euras. J. Scient. Res. 3, 123-127, 2008.

[7] A. A. Said, A. A. M. Aly, M. M. M. Abd El-Wahab, S. A. Soliman, A. A. Abd El-Hafez, V. Helmey, M. N. Goda, "Potential application of propionic acid modified sugarcane bagasse for removal of basic and acid dyes from industrial wastewater", Resources and Environment 2, 93-99, 2012.

[8] A. A. Said, A. A. M. Aly, M. M. M. Abd El-Wahab, S. A. Soliman, A. A. Abd El-Hafez, V. Helmey, M. N. Goda, Application of modified bagasse as a biosorbent for reactive dyes removal from industrial waste water", Journal of water resource and protection 5, 10-17, 2013.

[9] R. Gong, Y. Jin, F. Chen, J. Chen, Z. Liu, Enhanced malachite green removal from aqueous solution by citric acid modified rice straw. Journal of Hazardous Materials 137, 865-870, 2006.

[10] S. S. Azhar, A. G. Liew, D. Suhardy, K. F. Hafiz, M. D. I. Hatim, Dye removal from aqueous solution by using adsorption on treated sugarcane bagasse. American Journal of Applied Science 2, 1499-1503, 2005.

[11] Y. Safa, H. N. Bhatti, Adsorptive removal of direct textile dyes by low cost agricultural waste: Application of factorial design analysis, Chem. Ingin. J, 167, 35-41, 2011.

[12] M. Arami, N. Y. Limaee, N. M. Mahmoodi, N. S. Tabrizi, Removal of dyes from colored textile wastewater by orange peel adsorbent: equilibrium and kinetic studies. Journal of Colloids and Interface Science. 288, 371-376, 2005.

[13] G. Annadurai, R.-S. Juang, D.-J. Lee, Use of Cellulose-based wastes from adsorption of dyes from aqueous solutions. Journal of Hazardous Materials 92, 263-274, 2002.

[14] A. El-Nemr, O. Abdel wahab, A. El-Sikaily and A. Khaled, Removal of direct blue 86 from aqueous solution by new activated carbon developed from orange peel. Journal of Hazardous Materials 161, 102-110, 2009.

[15] P. K. Malik, Use of activated carbons prepared from saw dust and rice-husk for adsorption of acid dyes. Dyes and Pigments, $56,239-249,2003$.

[16] F. Colak, N. Atar, Biosorption of acidic dyes from aqueous solution by Paenibacillus macerans: Kinetic, thermodynamic and equilibrium studies, Chem. Eng. J. 150, 122-130, 2009.

[17] M. Ozacar, I. A. Sengil, Adsorption of metal complex dyes from aqueous solutions by pine sawdust. Bioresource Technology 96, 791-795, 2005.

[18] W. J. Weber Jr. and J. C. Morris, Kinetics and adsorption on carbon from solution. Journal of the sanitary Engineering Division 89, 31-60, 1963.

[19] K. Kannan and M. M. Sundaram, kinetics and mechanism of removal of methylene blue by adsorption on various carbons A comparatiestudy, Dyes and Pigments 51,25-40, 2001.

[20] R. Gong, Y. Liu, Y. Jiang, C. Li, Isothermal kinetic and thermodynamic studies on basic dye sorption onto tartaric acid esterified wheat straw. African Journal of Biotechnology. $8,7138-7147,2009$

[21] C. Namasivayam, D. Prabha, M. Kumutha, Removal of direct red and acid brilliant blue by adsorption onto banana pith. Bioresour. Technol., 64, 77-79, 1998.

[22] Y. Fu and T. Viraraghavan, Removal of congo red from an aqueous solution by fungus Aspergillus niger. Adv. Environ. Res., 7, 239-247, 2002.

[23] C. Namasivayam and N. Kanchana, Removal of congo red from aqueous solution by waste bannan pith, Pertanika J. Sci. Technol., 1, 32-42, 1993.

[24] V. N. Singh, G. Mishar, K. K. Panday, Removal of congo red by wollastonite, Indian J. Technol., 22, 70-71, 1994. 